\title{
Development and application of assay for determining $\beta$-glucosidase activity in human saliva
}

\author{
Lauren Stradwick', Debbie Inglis ${ }^{1,2,3}$, Jennifer Kelly ${ }^{1}$ and Gary Pickering ${ }^{2,3,4^{*}}$ (D)
}

\begin{abstract}
Background: $\beta$-glucosidase is an enzyme important to flavour enhancement. It hydrolyzes glucosides to release aglycones - aroma precursors that are bound to a sugar molecule — thereby making them available to contribute to the flavour of foods and beverages. While there is strong interest within the food and beverage industry to optimizing flavour through the use of exogenous and endogenous glucosidase in production, little is known regarding the possible occurrence of these enzymes within the human oral cavity. This could be an important source of flavour release and/or account for some differences between individuals in flavour perception. In the present study, we determined whether $\beta$-glucosidase is present in human saliva. First, an existing spectrophotometric assay that uses p-nitrophenyl- $\beta$-O-D-glucopyranoside as a substrate was modified and optimized for use in human saliva. The following variables were evaluated and where necessary, optimized: linearity of the assay signal, possible matrix interference, the effect of heat inactivation of the saliva, absorbance wavelength maxima, substrate saturation concentration, maximum saliva volume and the inclusion of a-cyclodextrin. The modified assay was then used to screen for $\beta$-glucosidase activity in the saliva of 20 individuals. Of the 20 samples analyzed, four were tentatively identified as containing active $\beta$-glucosidase and were further investigated.

Results: Significant differences $(p<0.05)$ in absorbance values $\left(A 400_{n m}\right)$ between these saliva samples confirm low levels of $\beta$-glucosidase activity in approximately $20 \%$ of the population sampled.

Conclusions: Inter-individual variability exists in $\beta$-glucosidase activity within the oral cavity. The described method can be applied to rapidly assay a large population of individuals, and further elucidate the extent and significance of salivary $\beta$-glucosidase activity within the context of human flavour perception and enhancement.
\end{abstract}

Keywords: $\beta$-Glucosidase assay, Salivary hydrolysis, Flavour enhancement, Human flavour perception, Wine

\section{Background}

Flavour, a product of the integration of distinct physiologically defined sensory systems that combine taste, aroma and trigeminal sensations [1], is a key determining factor for the acceptance of food and beverages by consumers [2]. Flavour is a dynamic process; a series of events that involves the interaction of the product and the consumer [3]. Characteristic flavour and aroma profiles of food and beverages arise from the composition and concentration of the volatile

\footnotetext{
* Correspondence: gpickering@brocku.ca

${ }^{2}$ Department of Biological Sciences, Brock University, 1812 Sir Isaac Brock

Way, St. Catharines, Ontario L2S 3A1, Canada

${ }^{3} \mathrm{Cool}$ Climate Oenology and Viticulture Institute, Brock University, 1812 Sir

Isaac Brock Way, St. Catharines, Ontario L2S 3A1, Canada

Full list of author information is available at the end of the article
}

compounds present. Volatility refers to the ease of evaporation of a compound into the air, which allows for the volatile constituents to enter and move within the nasal or oral cavities where they can bind to olfactory receptors and elicit an olfactory response [4]. Also contributing to potential flavour are non-volatile compounds, some of which while not odour-active can be broken down to release volatile odorants. These non-volatile constituents are known as aromatic precursors, and their potential is realized when the flavour compound-the aglycone-is released from its glycosidically bound form [5]. A glycoside is a compound composed of both a carbohydrate (glycone) and noncarbohydrate (aglycone) residue within the same molecule. When the glycone portion of the glycoside is a glucose 
molecule, the compound is known as a glucoside [6]. The ratio of glycosidically bound aroma compounds to their free aroma compound counterparts is dependent on the matrix. For example, in Muscat and Riesling wine grape varieties, this ratio ranges between 1 and 5 , whereas in the Gewürztraminer variety, bound compounds are up to 15 times more abundant than the free forms [7]. Thus, glycosidically bound compounds constitute a considerable reservoir of potential aromatic compounds that may enhance food and beverage flavour if their release can be realized. Glycosides can be separated from their sugar moieties through the use of heat, acid and enzyme hydrolysis [8], with the enzymes responsible for the latter known as glycoside hydrolases or glycosidases [9].

Juice and wine are two products that have been extensively studied with respect to glycosidically bound aroma precursors [10]. For instance, monoterpenes are important aglycone compounds that contribute to the flavour, aromatics and typicity of many grape varieties and their wines [5]. They exist in both a free volatile form, which can directly contribute to the aroma and flavour, and in a potentially volatile, glycosylated form, which are bound to either mono or disaccharides $[5,11]$. Other examples of grape berry-derived aglycones that contribute to flavour include terpenolds, C13-norisoprenoids and benzene derivatives [12]. These examples elicit mostly pleasant aromas that contribute to the aroma profile and have a low perception threshold [13].

Of the three methods by which glycosides can be separated, enzymatic hydrolysis is regarded as the most efficient, and considerable research has focused on its application to flavour enhancement [14]. Acid hydrolysis of glycosides occurs at a slow rate and may induce terpenol rearrangements $[13,15]$. Thermal hydrolysis has the potential to increase the breakdown of glycosides by $33 \%$; however, high temperatures can also rearrange the natural structure of the glycosides [16]. Generally, glycosidases are best characterized as the group of enzymes that act on disaccharides, oligosaccharides and polysaccharides [17] to specifically cleave the glycosidic bond present between the aglycone and the glycone of the glycoside structure $[6,9,18]$. They are able to catalyze the hydrolysis of both $S$ - and $O$-glycosidic linkages.

There is some evidence that human saliva may be involved with the release of non-volatile aroma compounds from glycoside structures. Saliva is a complex, heterogeneous, dilute aqueous solution that contains secretions from both the major and minor glands, including numerous inorganic salts, microorganisms, crevicular fluid, sloughed cells/food debris and a diverse selection of organic compounds such as proteolytic enzymes and mucous glucoproteins [19, 20]. In the mouth, flavour release from food and beverages is a dynamic process influenced by factors such as release rates of odorants, matrix compounds, breathing, mastication and saliva flow $[2,20]$. For non-volatile constituents, including aroma precursors, saliva acts as a carrier of the compounds to the taste buds located throughout the oral cavity, which is necessary to elicit a taste response [4]. Further, odour perception can be influenced by the length of time odour compounds persist after food or beverages are swallowed, by remaining in the oral cavity. Saliva plays a role in the intensity and duration of this aftertaste; it acts as a transport system by extracting odorants from materials that are not swallowed [21].

Most research to date on salivary enzymes, including $\beta$-glucosidase, has focused on their role in the diagnosis of periodontal disease [22] and responses to its treatment [23]. Few studies appear on the possible activity and prevalence of $\beta$-glucosidase in human saliva. Menguy et al. [24] suggested that approximately one in five people possess $\beta$-glucosidase in their saliva; however, the sample size of their study was quite small. Later, Arnaldos et al. [25] modified a spectrophotometric assay for strawberry callus protein for potential application in determining $\beta$-glucosidase in human saliva.

The optimal $\mathrm{pH}$ for $\beta$-glucosidase activity is approximately 5.5, with an activity range of 4.3-7.0 and an optimal temperature of $45{ }^{\circ} \mathrm{C}$ [26]. Varying activity of $\beta$ glucosidase within human saliva could represent a potential source of individual variation in the perception of flavour. Individual differences in flavour perception have been strongly linked to variation in food/beverage preferences, as well as habitual diet-related nutrition and health outcomes [27-31]. $\beta$-Glucosidase activity may increase the concentration of free volatile compounds available in the oral cavity through the hydrolysis of glycosidically bound non-volatiles, potentially enhancing flavour and overall perception of the food or beverage consumed.

Existing analytical methods for measuring $\beta$ glucosidase activity often require expensive, specialized equipment such as that used for high performance liquid chromatography (HPLC) [32]. Experimental methods and data analysis can be time-consuming with such techniques and require highly trained personnel. Further, current enzymatic approaches require extended incubation times and are highly temperature dependent [26]. The first objective of this study is to optimize an enzymatic method for measuring human salivary $\beta$-glucosidase activity that is rapid, simple and uses ubiquitous laboratory equipment (a spectrophotometer). A secondary objective is to apply this method to determine the prevalence of salivary $\beta$-glucosidase activity in humans. This research informs wider goals of fully eliciting the determinants of human flavour perception and sources of individual differences. 


\section{Methods}

\section{Assay development and validation}

A method to measure $\beta$-glucosidase activity from solubilized strawberry callus protein developed by Arnaldos et al. [25] was evaluated and modified for use in human saliva. The reagents were $6 \mathrm{mM}$ p-nitrophenyl- $\beta-O-\mathrm{D}-$ glucopyranoside (Sigma Aldrich, St. Louis, MO, USA), $6 \mathrm{mM} \alpha$-cyclodextrin (Sigma Aldrich, St. Louis, MO, USA), 0.025 units of almond $\beta$-glucosidase (Sigma Aldrich, St. Louis, MO, USA) and 0.1 M phosphate buffer $\mathrm{pH}$ of 6.5 , used to correct to a total volume of $2 \mathrm{~mL}$. $\alpha$ Cyclodextrin was included as it is reported to increase the sensitivity of the assay [25]. One enzyme unit is defined as the protein that hydrolyzes $1 \mu \mathrm{mol}$ of salicin per minute at $\mathrm{pH} 5$ and $37^{\circ} \mathrm{C}$. The absorbance of the released p-nitrophenol from the substrate was monitored at $405 \mathrm{~nm}$ over the course of $5 \mathrm{~min}$. The assay was evaluated and modified to measure $\beta$-glucosidase activity in human saliva with foci on (i) the time over which the assay gave a linear response; (ii) interference from human saliva; (iii) the absorbance wavelength maxima of p-nitrophenol; (iv) the substrate concentration required for saturation of the enzyme; (v) the maximum volume of saliva that could be used without causing interference and (vi) the effectiveness of $\alpha$-cyclodextrin in enhancing the absorbance signal. Thus, the experimental plan consisted of six factors assessed in two trials, in order to develop an assay to detect $\beta$-glucosidase activity in human saliva. All assays were performed in duplicate using a Spectronic Genesys 2 spectrophotometer and results presented as averages \pm standard deviation (SD), unless otherwise indicated. Table 1 summarizes the steps in developing and validating the assay.

\section{Saliva collection and processing \\ Trial 1}

A population of 20 healthy individuals (13 females, 7 males; 16 Caucasian, 4 non-Caucasian; $29.2 \pm 9.7$ years, range 21-53 years) free from oral disease participated in this trial by donating saliva samples. On the day of collection, participants were instructed to follow their normal morning routine (example: eating breakfast and brushing their teeth) and were asked to abstain from food or beverage for $2-3 \mathrm{~h}$ before sample collection. All $\beta$-glucosidase activities were assayed from fresh saliva specimens. We followed the protocols of Soderling [33] for the collection and processing of the saliva samples. Specifically, individuals were asked to spit into a $50-\mathrm{mL}$ falcon tube over the course of approximately $5 \mathrm{~min}$ until a minimum volume of $5 \mathrm{~mL}$ of saliva was collected. Samples were then centrifuged at $8000 \mathrm{rpm}$ in an SS34 rotor in a Sorval RC5C Plus at $4{ }^{\circ} \mathrm{C}$. The supernatant

Table 1 Experimental design for assay development

\begin{tabular}{|c|c|c|c|c|}
\hline & Experiment & Factors & Treatments & Outcome \\
\hline $\mathrm{i}$ & $\begin{array}{l}\text { Validate linearity } \\
\text { of the assay signal }\end{array}$ & $\begin{array}{l}7.75 \mathrm{mM} \text { p-nitrophenyl- } \beta-O-\mathrm{D}-\text { glucosidase } \\
+0.0025 \text { units of almond } \beta \text {-glucosidase, } \\
\text { corrected to final volume of } 2 \mathrm{~mL} \text { with } \\
100 \mathrm{mM} \text { phosphate buffer ( } \mathrm{pH} 6.5 \text { ); } \\
\text { wavelength } 400 \mathrm{~nm} \text { over } 10 \mathrm{~min} ; \\
\text { no a-cyclodextrin }\end{array}$ & $\begin{array}{l}\text { Absorbance measured every } \\
\text { minute for } 10 \text { min after the } \\
\text { addition of almond } \beta \text {-glucosidase }\end{array}$ & $\begin{array}{l}\text { Linearity of the assay } \\
\text { is confirmed }\end{array}$ \\
\hline ii & $\begin{array}{l}\text { Assess interference } \\
\text { from saliva }\end{array}$ & See (i) above & $\begin{array}{l}\text { Absorbance values of buffer } \\
\text { compared with and without } 25 \mu \mathrm{L} \\
\text { heat-inactivated }{ }^{\text {a }} \text { human saliva }\end{array}$ & $\begin{array}{l}\text { Heat-inactivated saliva does } \\
\text { not interfere with the matrix }\end{array}$ \\
\hline iii & $\begin{array}{l}\text { Determine absorbance } \\
\text { maxima of p-nitrophenyl }\end{array}$ & See (i) above & Assay measured at 400 and 405 nm & $400 \mathrm{~nm}$ selected \\
\hline iv & $\begin{array}{l}\text { Determine substrate } \\
\text { saturation concentration }\end{array}$ & $\begin{array}{l}\text { Varying substrate concentrations }+0.0025 \\
\text { units of almond } \beta \text {-glucosidase, corrected } \\
\text { to final volume of } 2 \mathrm{~mL} \text { with } 100 \mathrm{mM} \\
\text { phosphate buffer (pH 6.5); wavelength } \\
400 \mathrm{~nm} \text { over } 10 \mathrm{~min}\end{array}$ & $\begin{array}{l}\text { Substrate concentration varied } \\
\text { between } 0 \text { and } 10 \mathrm{mM}\end{array}$ & $7.75 \mathrm{mM}$ selected \\
\hline v & $\begin{array}{l}\text { Determine maximum } \\
\text { saliva volume }\end{array}$ & $\begin{array}{l}7.75 \mathrm{mM} \text { p-nitrophenyl- } \beta-O-D \text {-glucosidase } \\
+0.0025 \text { units of almond } \beta \text {-glucosidase } \\
+ \text { varying volumes of heat-inactivated saliva, } \\
\text { corrected to final volume of } 2 \mathrm{~mL} \text { with } \\
100 \mathrm{mM} \text { phosphate buffer ( } \mathrm{pH} 6.5 \text { ); } \\
\text { wavelength } 400 \mathrm{~nm} \text { over } 10 \mathrm{~min}\end{array}$ & $\begin{array}{l}\text { Different amounts of heat-inactivated } \\
\text { saliva evaluated: } 25,50,100,150 \\
\text { and } 200 \mu \mathrm{L}\end{array}$ & $200 \mu \mathrm{L}$ selected \\
\hline vi & $\begin{array}{l}\text { Evaluate efficacy of } \\
\text { a-cyclodextrin }\end{array}$ & $\begin{array}{l}7.75 \mathrm{mM} \text { p-nitrophenyl- } \beta-0 \text {-D-glucosidase } \\
+0.0025 \text { units of almond } \beta \text {-glucosidase } \\
+200 \mu \mathrm{L} \text { of heat-inactivated saliva, } \\
\text { corrected to final volume of } 2 \mathrm{~mL} \text { with } \\
100 \mathrm{mM} \text { phosphate buffer }(\mathrm{pH} 6.5) ; \\
\text { wavelength } 400 \mathrm{~nm} \text { over } 10 \mathrm{~min}\end{array}$ & $\begin{array}{l}\text { Assays performed with and } \\
\text { without } 6 \mathrm{mM} \text { a-cyclodextrin }\end{array}$ & $\begin{array}{l}\text { Inclusion of } 6 \mathrm{mM} \\
\text { a-cyclodextrin in assay }\end{array}$ \\
\hline
\end{tabular}


was transferred into 1.5-mL Eppendorf tubes, placed on ice and assayed within $2 \mathrm{~h}$ of sample collection.

\section{Trial 2}

Four saliva samples with high rates of enzymatic activity were re-evaluated by processing the saliva with two additional treatments. For the first treatment, the saliva was re-centrifuged for $10 \mathrm{~min}$ at $8000 \mathrm{rpm}$ (SS-34 rotor in a Sorval RC5C Plus centrifuge). The clarified supernatant was placed on ice and assayed within $2 \mathrm{~h}$ of processing. The second treatment used the saliva collection and centrifugation method outlined in Trial 1, then the saliva was heat-inactivated at $100{ }^{\circ} \mathrm{C}$ for $10 \mathrm{~min}$. The heatinactivated samples were then placed on ice and assayed within $2 \mathrm{~h}$.

\section{Statistical analysis}

Differences between variables were determined using the XLSTAT statistical software package (Addinsoft, Version 7.1; New York, NY, USA). Statistical methods used were analysis of variance (ANOVA) with mean separation by Tukey's honestly significant difference (HSD) test $(p<$ 0.05) and linear regression analysis.

\section{Results}

\section{Assay development and validation}

The hydrolysis reaction of the p-nitrophenyl- $\beta-O-D-g l u-$ copyranoside by almond $\beta$-glucosidase is linear for the first $10 \mathrm{~min}$ of the reaction (linear regression analysis, $R^{2}$ value of 0.999; data not shown). Both the $0.1 \mathrm{M}$ phosphate buffer and the $0.1 \mathrm{M}$ phosphate buffer containing $25 \mu \mathrm{L}$ of heat-inactivated saliva spiked with 0.025 units of almond $\beta$-glucosidase show no significant difference in their change in absorbance over the first $10 \mathrm{~min}$. This assay was also performed with both heat-inactivated and non-heat-inactivated human saliva without the presence of almond $\beta$-glucosidase, and no significant change in absorbance was observed (Fig. 1).

Due to different reported values for the p-nitrophenol wavelength maxima (405 nm, [25]; $400 \mathrm{~nm}$, [34]), we measured almond $\beta$-glucosidase activity using $0.1 \mathrm{M}$ phosphate buffer as well as $0.1 \mathrm{M}$ phosphate buffer containing $25 \mu \mathrm{L}$ of heat-inactivated human saliva at both 400 and $405 \mathrm{~nm}$. There was no significant difference between the reaction rates observed for each wavelength for either matrix (Fig. 2). Therefore, for the measurement of $\beta$-glucosidase activity in human saliva, we used $400 \mathrm{~nm}$ as the p-nitrophenol wavelength maxima.

To examine the substrate saturation concentration, we varied the concentration of $\mathrm{p}$-nitrophenyl- $\beta$ - $O$-D-glucopyranoside in $25 \mu \mathrm{L}$ of heat-inactivated human saliva between 0 and $10 \mathrm{mM}$. Figure 3 shows the change in absorbance at $400 \mathrm{~nm}$ plotted against the time frame of the reaction. The plateau (representing substrate saturation) occurs at 6-8 $\mathrm{mM}$ of p-nitrophenyl- $\beta$ - $O$-D-glucopyranoside, indicating that a concentration of substrate between 6 and $8 \mathrm{mM}$ in the $\beta$-glucosidase assay will allow for the maximum rate of hydrolysis.

An assay was performed using five different volumes of heat-inactivated human saliva $(25,50,100,150$ and $200 \mu \mathrm{L}$ ) each spiked with 0.025 units of almond $\beta$ glucosidase to determine maximum saliva concentrations. The reaction rates did not differ between volumes $(F=2.3(4,5) ; p=0.19)$ (data not shown). Therefore, to maximize the level of $\beta$-glucosidase activity (predicted to be low) that could be detected in human saliva, the maximum volume of $200 \mu \mathrm{L}$ for each human saliva sample was used.

We also assessed the effectiveness of $\alpha$-cyclodextrin in enhancing the absorbance signal of the p-nitrophenol- $\alpha$ cyclodextrin chromophore by measuring absorbance in the presence and absence of $6 \mathrm{mM}$ of $\alpha$-cyclodextrin.

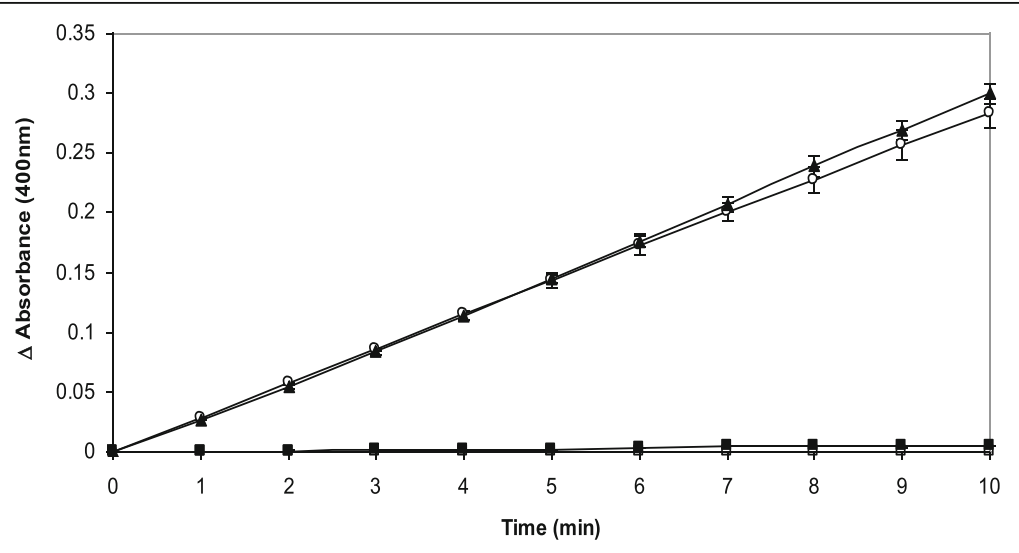

Fig. 1 Almond $\beta$-glucosidase activity in the presence and absence of heat-inactivated human saliva. Almond $\beta$-glucosidase was measured in a reaction containing phosphate buffer (o) and phosphate buffer with $25 \mu \mathrm{L}$ of heat-inactivated human saliva $(\mathbf{\Lambda})$. The background activity of the heat inactivated saliva (-) and phosphate buffer both without almond $\beta$-glucosidase ( $\square$ ) were also measured. Each treatment and time point was measured in duplicate. The data points represent average values \pm SD 


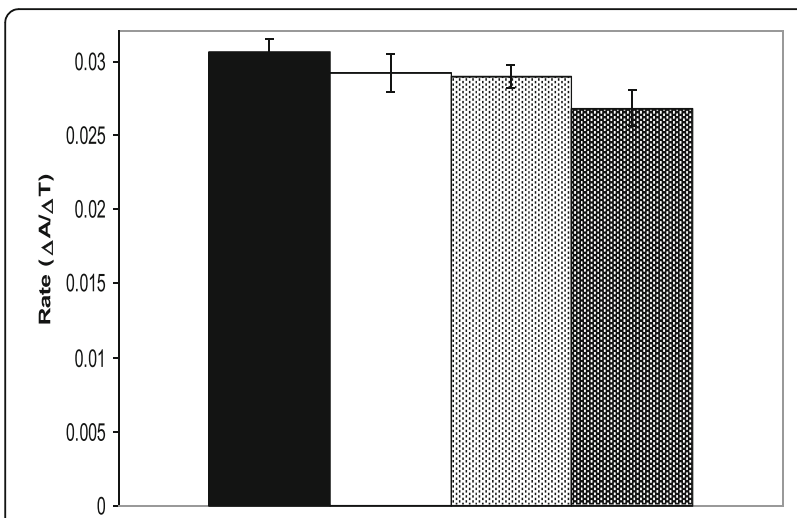

Fig. 2 Comparison of almond $\beta$-glucosidase activity measured at 400 and $405 \mathrm{~nm}$. Measured in a reaction containing phosphate buffer or phosphate buffer with $25 \mu \mathrm{L}$ of heat-inactivated human saliva. Enzyme activity was measured in both the inactive saliva and phosphate buffer at $400 \mathrm{~nm}(\mathbf{-}$, 口) and $405 \mathrm{~nm}$ ( , , respectively. The rate of reaction displayed on the $y$-axis in units of change in absorbance per change in time (minutes). The data points represent average values $\pm S D$

Absorbance was increased two-fold when $\alpha$-cyclodextrin is included in the $\beta$-glucosidase assay at a concentration of $6 \mathrm{mM}(0.056 \pm 0.001$ versus $0.028 \pm 0.000)$ (data not shown). This is further demonstrated by the change in molar absorption coefficients of p-nitrophenol $(7.75 \mathrm{mM})$ and the $\alpha$ cyclodextrin $(6 \mathrm{mM}) / \mathrm{p}$-nitrophenol $(7.75 \mathrm{mM})$ complex measured in heat-inactivated human saliva and calculated using the Beer-Lambert Law $(A=\varepsilon \mathrm{cl})$ : p-nitrophenol absorbance, $0.0277\left(=3.57 \mathrm{Lmol}^{-1} \mathrm{~cm}^{-1}\right), \alpha$-cyclodextrin/p-nitrophenol complex absorbance, $0.0563\left(=7.26 \mathrm{Lmol}^{-1} \mathrm{~cm}^{-1}\right)$.

Given these findings, the optimized method for determining $\beta$-glucosidase activity in human saliva was as follows: $7.75 \mathrm{mM}$ of p-nitrophenyl- $\beta$-O-D-glucopyranoside (Sigma Aldrich, St. Louis, MO, USA), $6 \mathrm{mM}$ of $\alpha-$ cyclodextrin (Sigma Aldrich, St. Louis, MO, USA), $200 \mu \mathrm{L}$ of human saliva, $0.1 \mathrm{M}$ phosphate buffer at $\mathrm{pH}$
6.5 (used to correct to a total volume of $2 \mathrm{~mL}$ ) and absorbance measured at wavelength of $400 \mathrm{~nm}$.

\section{Application: prevalence of $\beta$-glucosidase in human saliva} The optimized and validated method described above was used to examine $\beta$-glucosidase activity in the saliva of 20 individuals. The results are presented in Fig. 4. As can be noted, there was a large and statistically significant variation in activity between individual saliva samples $(p<0.05)$. Some activity is suggested in 19 of the 20 samples, with four in particular showing relatively high values.

As participants 8, 9, 11 and 12 show significantly higher reaction rates than others, we conducted further testing to ensure that other components of the saliva matrix were not interfering, that $\beta$-glucosidase was in fact being measured, and to determine whether or not the samples were following a typical pattern of enzyme activity. These samples were evaluated with additional treatments to confirm that the change in absorbance was due to the hydrolysis of the p-nitrophenyl- $\beta-O-\mathrm{D}-$ glucopyranoside. The reaction time frame was extended to $30 \mathrm{~min}$ to observe the enzyme activity pattern. Treatments $(1 \times 10 \mathrm{~min}$ of centrifugation, $2 \times 10 \mathrm{~min}$ of centrifugation and $1 \times 10 \mathrm{~min}$ of centrifugation plus $10 \mathrm{~min}$ in a $100{ }^{\circ} \mathrm{C}$ water bath) and results are shown in Fig. 5.

Figure 5 illustrates that the change in absorbance does not increase linearly after approximately $10 \mathrm{~min}$, representative of a classic enzyme curve. Individuals 8, 9 and 12 display similar levels of $\beta$-glucosidase activity as in Trial 1 , whereas absorbance values for individual 11 show an approximate two-fold decrease between the two trials.

\section{Discussion}

The first phase of this study sought to adapt and validate the assay developed by Arnaldos et al. [25] for measuring $\beta$-glucosidase activity in a non-saliva matrix to whole

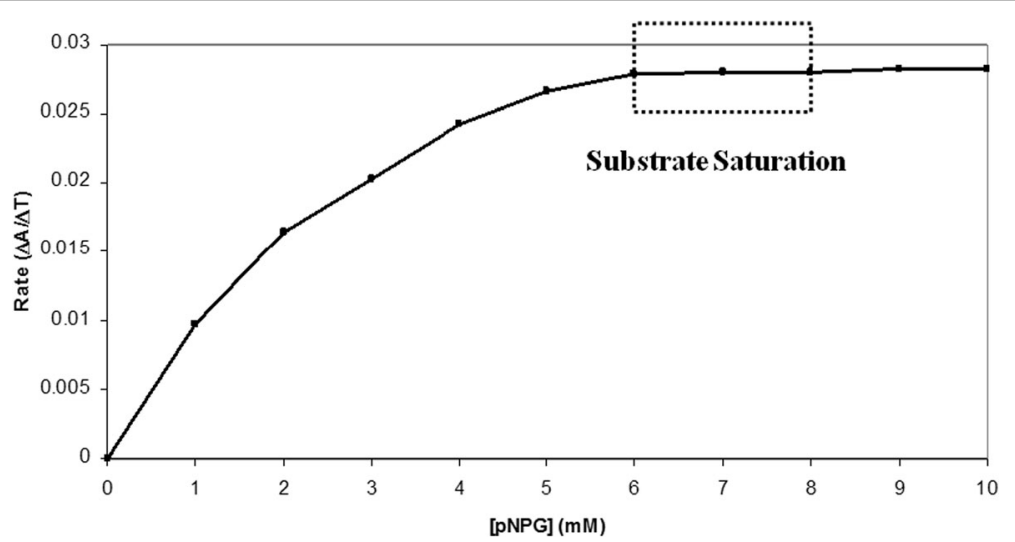

Fig. 3 Determining the saturating substrate concentration for the $\beta$-glucosidase assay with $25 \mu \mathrm{L}$ of inactivated human saliva by varying the concentration of the $\mathrm{p}$-nitrophenyl- $\beta$-O-D-glucopyranoside substrate from 0 to $10 \mathrm{mM}$ over $10 \mathrm{~min}$ 


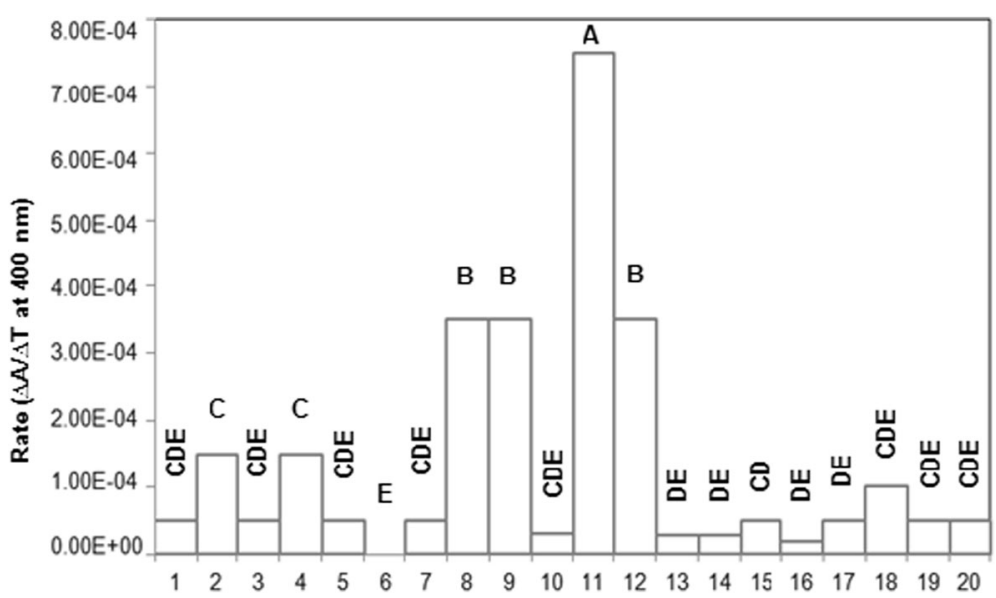

Fig. $4 \beta$-glucosidase activity in 20 human saliva samples. Two control assays were performed using $0.1 \mathrm{M}$ phosphate buffer with and without $25 \mu \mathrm{L}$ almond $\beta$-glucosidase. The rate of reaction displayed on the $y$-axis is in units of change in absorbance per change in time (minutes). The samples are labelled 1-20. Samples with different letters (A-E) have significantly different rates (Tukey HSD $\mathrm{D}_{0.05}$ )

human saliva. Reproducible and reliable performance was obtained using $0.1 \mathrm{M}$ phosphate buffer, 0.025 units almond $\beta$-glucosidase, $7.75 \mathrm{mM}$ p-nitrophenyl- $\beta$-O-Dglucopyranoside, $6 \mathrm{mM}$ of $\alpha$-cyclodextrin, $200 \mu \mathrm{L}$ saliva and a wavelength of $400 \mathrm{~nm}$. Importantly, we show that the inclusion of $6 \mathrm{mM}$ of $\alpha$-cyclodextrin increases the sensitivity of the assay, and that inclusion of heatinactivated human saliva is a necessary component of the new method. As observed in Fig. 5, heat inactivation reduced the activity level in the saliva, indicating there is a background hydrolysis of the substrate that is not due to $\beta$-glucosidase activity. The difference in activity between the non-heat-treated saliva and the heat-treated sample represents the $\beta$-glucosidase activity in the saliva. This result shows the importance of subtracting out any contribution of substrate hydrolysis from a heat-

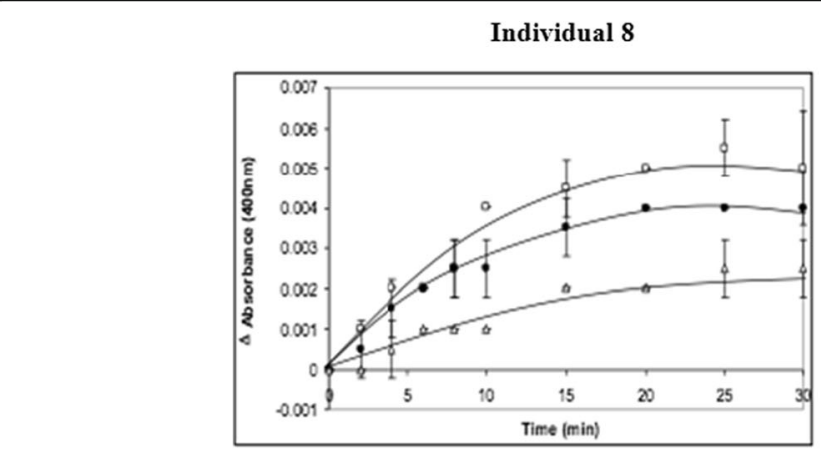

Individual 11

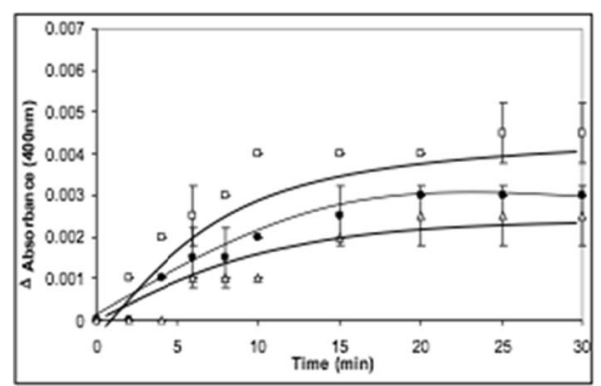

Individual 9

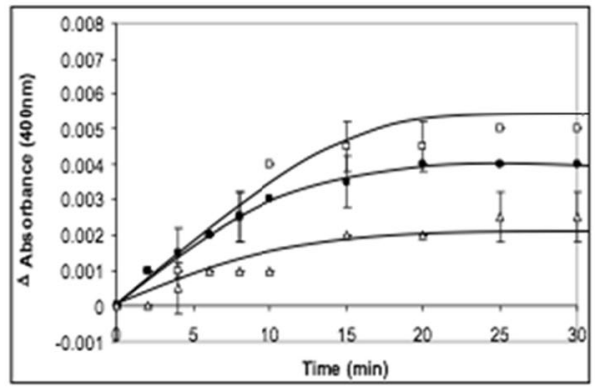

Individual 12

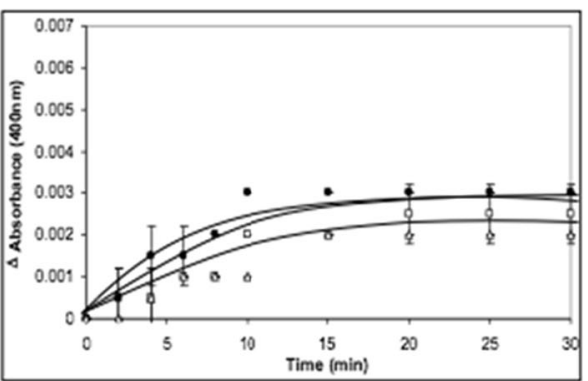

Fig. 5 Retesting of four saliva samples to evaluate $\beta$-glucosidase activity in saliva over a 30-min time period. After 10 min of centrifugation ( $\square$ ), after $2 \times 10$ min of centrifugation $(\bullet)$ and after $10 \mathrm{~min}$ of centrifugation and $10 \mathrm{~min}$ of heat inactivation $(\Delta)$. The data points represent average values \pm SD 
inactivated sample to ensure all background hydrolysis is accounted for and only $\beta$-glucosidase activity is being reported. An existing study conducted by Walle et al. [35] also evaluated human saliva for $\beta$-glucosidase activity via high performance liquid chromatography (HPLC), with a minimum detectable amount of $1 \mu \mathrm{mol} /(\mathrm{L}$ saliva $\times \mathrm{h}$ ). Their method measured the hydrolysis of the flavonoid glucoside genistin as a proxy for enzyme activity. Evidence from other studies [36, 37] suggests that HPLC and spectrophotometric analysis are equally accurate (based on recovery methods), but HPLC may be less variable than spectrophotometric measurements. However, given the rapid nature of our modified spectrophotometric assay, its ease of use, the time required to run analyses and the reduced associated costs, it offers an attractive option for analysis of $\beta$-glucosidase activity in human saliva.

The second aim of this study was to assess the prevalence of salivary $\beta$-glucosidase activity in a sample of 20 individuals. The accuracy of the spectrophotometer is \pm 0.003 absorbance units in the absorbance range being measured. Given this measurement uncertainty, only four of the 20 samples examined appear to contain $\beta$ glucosidase activity (absorbance values greater than $3 \times$ 10e-4 absorbance units). Fresh saliva samples were obtained and re-evaluated from these individuals, with the resultant absorbance: time responses consistent with classic enzyme activity curves, further suggesting there is active $\beta$-glucosidase in these samples.

This relatively low prevalence of human salivary $\beta$ glucosidase activity is consistent with the findings of Menguy et al. [24] (1 from 5 individuals) and Zambon et al. [23] (0 from 5 individuals). The aforementioned study by Walle et al. [35] measured the rates of enzymatic hydrolysis in 17 individuals; three individuals showed very high rates (defined by consumption of substrate), one individual showed no hydrolysis and the remainder fell within a range of barely detectable to moderate levels of hydrolysis. Given the similarity of these results to those obtain in the current study, the literature is now converging around an incidence of $\beta$-glucosidase activity in human saliva of approximately $20 \%$.

Human salivary $\mathrm{pH}$ ranges from 6.2 to 7.4 [38], encompassing the upper limits of the $\beta$-glucosidase $\mathrm{pH}$ activity range $(4.3-7.0$; optima $=5.5)$ [26]. It is therefore possible that $\beta$-glucosidase activity and potentially flavour perception may be more pronounced in individuals with low relative salivary $\mathrm{pH}$. However, this speculation should be considered in the context of the $\mathrm{pH}$ of the food or beverage containing the glucosides. For instance, the buffering capacity of wine has been shown in both in vitro and in vivo studies to be superior to that of saliva; the $\mathrm{pH}$ of wine/saliva mixtures in the mouth is essentially that of the wine (3.4-3.8) [39], presumably negating any individual differences in initial salivary $\mathrm{pH}$. Indeed, in the case of wine, this profound decrease in the $\mathrm{pH}$ of the saliva/wine mixture suggests that glucoside hydrolysis from $\beta$-glucosidase in this glucoside-rich beverage would be negligible.

In the present study, the absorbance readings for individual 11 varied approximate two-fold between the two evaluations, raising questions around the source of this day-to-day variability in activity and also why some individuals possess salivary $\beta$-glucosidases at all. Participants were instructed to brush their teeth and eat breakfast as usual the morning their saliva was collected. However, it is possible that those protocols were not followed, and information on the teeth brushing practices of participants was not collected. Bacterial flora in the oral cavity, bacteroides and shedded oral epithelial cells are potential sources of $\beta$-glucosidases, as shown by the effectiveness of antibacterial agents such as Listerine ${ }^{\circ}$ in inhibiting salivary hydrolysis, even $24 \mathrm{~h}$ after use [22, 35]. This could have a significant effect on the prevalence and extent of $\beta$-glucosidase activity reported here. For instance, some participants may have increased concentration of bacterial flora due to not brushing, while others may have used mouthwash and/or tooth brushing prior to samples being collected. Similarly, differences between replicate sample activities from the same individual(s) may be due to changes in daily oral hygiene practices. It is also possible that inter-individual variation in activity could have a genetic origin with, for instance, some individuals more predisposed to periodontal disease than others [22]. Finally, future research might also consider the association of demographic factors and dietary habits with variation in oral $\beta$-glucosidase activity.

\section{Conclusions}

This study successfully measured low levels of $\beta$ glucosidase activity in human saliva, with the estimated prevalence of $20 \%$ in agreement with other studies. Further research should establish the ecological significance of this finding; that is, whether individuals with significant levels of salivary $\beta$-glucosidase activity gain any flavour advantage or perceive components of flavour differently. Time-intensity methodologies, including temporal dominance approaches, may be helpful in this regard. The rapid assay developed and described here offers an inexpensive alternative to HPLC methods for measuring $\beta$-glucosidase activity and can be applied to larger populations of individuals to further elucidate the extent and significance of human salivary $\beta$-glucosidase activity. This should provide additional insights into individual flavour perception and advance understanding of the role of flavour perception in food and beverage preferences and subsequent ingestion behaviours. 


\section{Abbreviations}

ANOVA: Analysis of variance; HPLC: High performance liquid

chromatography; HSD: Honestly significant difference; SD: Standard deviation

\section{Acknowledgements}

Jamie-Lee Robb is thanked for the editorial assistance, and the anonymous reviewers for the very helpful suggestions that have improved the manuscript.

\section{Funding}

We acknowledge the support of the Brock University Library Open Access Publishing Fund.

\section{Availability of data and materials}

The data supporting the conclusions of this article will be available in the Brock University digital repository (http://dr.library.brocku.ca/handle/10464/4).

\section{Authors' contributions}

DI and GP conceived the experiment. LS collected and analyzed the data. LS and JK prepared the manuscript, with contribution from DI and GP. All authors read and approved the final manuscript.

\section{Competing interests}

The authors declare that they have no competing interests.

\section{Ethics approval and consent to participate}

Ethics approval was obtained for this study through Brock University. Participants consented to participation in the study and saliva samples being taken

\section{Author details}

'Centre for Biotechnology, Brock University, 1812 Sir Isaac Brock Way, St Catharines, Ontario L2S 3A1, Canada. 'Department of Biological Sciences, Brock University, 1812 Sir Isaac Brock Way, St. Catharines, Ontario L2S 3A1, Canada. ${ }^{3} \mathrm{Cool}$ Climate Oenology and Viticulture Institute, Brock University, 1812 Sir Isaac Brock Way, St. Catharines, Ontario L2S 3A1, Canada. ${ }^{4}$ Charles Sturt University, Locked Bag 588, Wagga Wagga, New South Wales 2678, Australia.

Received: 5 May 2016 Accepted: 18 January 2017

\section{Published online: 01 February 2017}

\section{References}

1. Prescott J. Flavour as a psychological construct: implications for perceiving and measuring the sensory qualities of foods. Food Qual Prefer. 1999;10:349-56.

2. Buettner A, Schieberle P. Influence of mastication on the concentration of aroma volatiles-some aspects of flavour release and flavour perception. Food Chem. 2000:71:347-54

3. Piggot JR. Dynamism in flavour science and sensory methodology. Food Res Int. 2000;33:191-7.

4. Fisher C, Scott TR. Food flavours: biology and chemistry. Cambridge: The Royal Society of Chemistry. Cambridge, UK; 1997.

5. Gunata Z, Vallier MJ, Sapis JC, Bayonove C, Arnaudon V, Madarro A, Polaina J. Hydroylsis of monoterpenyl- $\beta$-D-glucosides by cloned $\beta$-Glucosidases from Bacillus polymyxa. Enzyme Microb Tech. 1996;18:286-90.

6. Chandler RF. Licorice more than just a flavour. Can Pharm J. 1985;1 18:420-4

7. Gunata Z, Bitteur S, Brillouet JM, Bayonove C, Cordonnier R. Sequential enzymic hydrolysis of potentially aromatic glycosides from grape. Carb Res. 1988:184:139-49.

8. Reineccius G. Flavour chemistry and technology. 2nd ed. Boca Raton: Taylor and Francis Group; 2006

9. Henrissat B, Davies G. Structural and sequence-based classification of glycoside hydrolases. Curr Opin Struct Biol. 1997;7:637-44.

10. Martino A, Durante M, Pifferi PG, Spagna G, Bianchi G. Immobilization of Bglucosidase from a commercial preparation. Part 1. A comparative study of natural supports. Process Biochem. 1996;31(3):281-5.

11. Wilson B, Strauss CR, Williams PJ. The distribution of free and glycosidicallybound monoterpenes among skin, juice, and pulp fractions of some white grape varieties. Am J Enol Vitic. 1986;37:107-11.

12. Mander L, Liu HW. Comprehensive natural products II: Chemistry and Biology. Kidlington: Elsevier Ltd.; 2010. p. 1189-93.

13. Li X, Long Lim S, Yu B, Curran P, Liu SQ. Mango wine aroma enhancement by pulp contact and $\beta$-glucosidase. Int J Food Sci Tech. 2013;48:2258-66.
14. Delcroix A, Gunata Z, Sapis JC, Salmon JC, Bayonove C. Glycosidase activities of three enological yeast strains during winemaking: effect of the terpenol content of Muscat wine. Am J Enol Vitic. 1994;45:291-6.

15. Mateo J, Di Stefano R. Description of the $\beta$-glucosidase activity of wine yeasts. Food Microbiol. 1997;14:583-91.

16. Zoecklein B, Marcy J, Jasinski Y. Effect of fermentation, storage sur lie or post-fermentation thermal processing on White Reisling (Vitis vinifera L.) glycoconjugates. Am J Enol Vitic. 1997;48:397-402.

17. Dayies GJ, Gloster TM, Henrissat B. Recent structural insights into the expanding world of carbohydrate-active enzymes. Curr Opin Struct Biol. 2005;15:637-45.

18. Henrissat B. A classification of glycosyl hydrolases based on amino acid sequence similarities. Biochem J. 1991:280:309-16.

19. Schwartz SS, Zhu WX, Sreebny LM. Sodium dodecyl sulphatepolyacrylamide gel electrophoresis of human whole saliva. Archs Oral Biol. 1995:40:949-58

20. Buettner A. Influence of human salivary enzymes on odorant concentration changes occurring in vivo esters and thiols. J Agric Food Chem. 2002;50: 3283-9.

21. Buettner A, Welle F. Intra-oral detection of potent odorants using a modified stir-bar sorptive extraction system in combination with HRGC-O, known as the buccal odour screening system (BOSS). Flavour Fragr J. 2004; 19:505-14.

22. Kaufman E, Lamster B. Analysis of saliva for periodontal diagnosis: a review. J Clin Periodontol. 2000;27:453-65.

23. Zambon JJ, Nakamura M, Slots J. Effect of periodontal therapy on salivary enzymatic activity. J Periodontal Res. 1985;20:652-9.

24. Menguy R, Masters YF, Desbaillets L. Human salivary glycosidases. Exper Biol Med. 1970;134:1020-5

25. Arnaldos T, Serrano M, Calderon A, Munoz R. A rapid and continuous spectrophotometric method to measure $\beta$-glucosidase activity based on $\mathrm{p}$ -

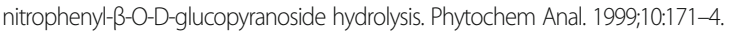

26. Matsuura M, Obata A. $\beta$-Glucosidases from soybeans hydrolyse daidzin and genistin. J Food Sci. 1993;58:144-7

27. Drewnowski A. Taste preferences and food intake. Annu Rev Nutr. 1997;17: 237-53.

28. Duffy V. Variation in oral sensation: implications for diet and health. Curr Opin Gastroenterol. 2007;23(2):171-7.

29. Tepper BJ. Nutritional implications of genetic taste variation: the role of PROP sensitivity and other taste phenotypes. Annu Rev Nutr. 2008;28:367-88.

30. Pickering GJ, Jain AK, Bezawada R. Segmentation and drivers of wine liking and consumption in US wine consumers. Int J Wine Res. 2014;9:9-19.

31. Pickering GJ, Hayes JE. The influence of biological, experiential and psychological factors in wine preference segmentation. Aust J Grape Wine Res. 2017. In Press

32. Baú TR, Ida El. Soymilk processing with higher isoflavone aglycone content. Food Chem. 2015;183:161-8.

33. Soderling E. Chapter 1: Practical aspects of salivary analyses. In: Tenovuo JO, editor. Human Saliva: Clinical Chemistry and Microbiology, vol. 1. Boca Raton: CRC Press Inc; 1989. p. 1-19.

34. Jyothirmayi N, Ramadoss CS. Evidence for beta-galactosidase catalyzed hydrolysis of paranitrophenyl-beta-D-galactopyranoside anchored in cyclodextrins. Indian J Biochem Biophys. 1993;30:218-30

35. Walle T, Browning AM, Steed LL, Reed SG, Walle UK. Flavonoid glucosides are hydrolyzed and thus activated in the oral cavity in humans. J Nutr. 2005; 135:48-52.

36. Kumar AKH, Sudha V, Swaminathan S, Ramachandran G. A comparison of HPLC \& spectrophotometric methods for estimation of antiretroviral drug content in pharmaceutical products. Indian J Med Res. 2010;132:390-4.

37. Costa César I, Nogueira FHA, Pianetti GA. Comparison of HPLC, UV spectrophotometry and potentiometric titration methods for the determination of lumefantrine in pharmaceutical products. J Pharmaceut Biomed. 2008;48:223-6.

38. Schipper R, Silletti E, Vingerhoeds M. Saliva as research material: biochemical, physicochemical and practical aspects. Arch Oral Biol. 2007:52: $1114-35$

39. Obreque-Slier E, Espínola-Espínola V, López-Solís R. Wine pH prevails over buffering capacity of human saliva. J Agric Food Chem. 2016;64:8154-9. 